\title{
The Welfare Cost of Inflation Risk Under Imperfect Insurance
}

\author{
Yann Algan* $\quad$ Olivier Allais $^{\dagger} \quad$ Edouard Challe ${ }^{\ddagger} \quad$ Xavier Ragot $^{\S}$
}

February 15, 2015

\begin{abstract}
What are the costs of inflation fluctuations and who bears those costs? In this paper, we investigate this question by means of a quantitative incomplete-market, heterogenous-agent model wherein households hold real and nominal assets and are subject to both idiosyncratic labor income shocks and aggregate inflation risk. Inflation risk is found to generates significant welfare losses for most households, i.e., between 1 and 1.5 percent of permanent consumption. The loss is small or even negative for households at the very top of the productivity and/or wealth distribution. A key feature of our analysis is a nonhomothetic specification for households' preferences towards money and consumption goods. Unlike traditional specifications, ours allows the model to reproduce the broad features of the distribution of monetary assets (in addition to being consistent with the distribution of nonmonetary assets).
\end{abstract}

JEL codes : E21; E32; E41

Keywords : Money-in-the-utility; incomplete markets; inflation risk; welfare.

*Sciences Po and CEPR; yann.algan@sciences-po.fr.

${ }^{\dagger}$ INRA; olivier.allais@ivry.inra.fr.

${ }^{\ddagger}$ Ecole Polytechnique, CREST and Banque de France; edouard.challe@gmail.com.

${ }^{\S}$ Paris School of Economics and OFCE; ragot@pse.ens.fr. 


\section{Introduction}

What are the costs of inflation fluctuations and who bears those costs? In this paper, we investigate this question by means of a quantitative incomplete-market, heterogenous-agent model wherein households hold real and nominal assets and are subject to both idiosyncratic labor income shocks and aggregate inflation risk. To be more specific, the model incorporates the following four main features:

First, households solve an optimal portfolio choice between money and capital claims, subject to an occasionally binding borrowing constraint. Both assets can coexist in household portfolios because the lower real return paid by money balances is compensated by the liquidity services that it provides - as captured by the fact that real money balances affect current utility, in the moneyin-the-utility, or "MIU" tradition. ${ }^{1}$ This feature is in contrast with existing incomplete-market models with aggregate shocks, which either abstract for portfolio choices (by considering a single asset or a menu of perfectly substitutable assets), or focuses on the choice between two real assets (so that inflation risk does not affect the relative returns of the assets). ${ }^{2}$

Second, the model is designed to match the cross-sectional distribution of money holdings, in addition to matching the cross-section of nonliquid wealth. Because our investigation is primarily quantitative, a prerequisite for a meaningful analysis of the impact of inflation risk on the welfare of different types of households is that the model match the cross-sectional distribution of monetary wealth in the first place. We show that this requirement requires departing from the functional form commonly used to parameterize money demand in monetary models with representative agent. ${ }^{3}$ As discussed extensively in Ragot (2014), the empirical cross-sectional distribution of money holdings in the US is close to that of financial assets and hence very different from that of consumption. ${ }^{4}$ This property cannot follow from the usual MIU specification, which features a constant elasticity

\footnotetext{
${ }^{1}$ This tradition goes back at least to Patinkin (1956) and Sidrauski (1967). See Walsh (2010) for a survey of the flexible-price MIU model under complete markets.

${ }^{2}$ In such models, when the borrowing constraint is not zero, private bonds are traded next to capital claims, but the two are usually assumed to be perfect substitutes (see, e.g., Krusell and Smith, 1998). Heathcote (2005) introduces government bonds next to the capital stock, but again makes the necessary assumptions ensuring that the two are perfect substitutes. Krusell and Smith (1997) consider the portfolio choice between a real riskless bond and capital claims. Krusell et al. (2011) and Challe et al. (2013) analyze the portfolio choice between real bonds (differing by their maturity).

${ }^{3}$ See, e.g., Chari et al. (1996, 2000).

${ }^{4}$ For example, Ragot (2014) finds that in the US Gini coefficient for individual consumption levels is 0.54 , while that for money balances is 0.85 . In Italy the corresponding figures are 0.30 and 0.68 , respectively.
} 
of substitution between money and goods and hence strict proportionality between the demands for money and consumption goods. In this where the case then inequalities in money holdings would simply mirror inequalities in consumption, which as already mentioned is strongly against the data. We overcome this limitation of the standard MIU specification by introducing a more general utility function that nests the constant-elasticity case but also accommodates a non-constant elasticity of substitution, thereby allowing individual money holdings to vary more than proportionally with individual consumption. This utility function allows us to reproduce the broad features of the distribution of monetary wealth in the US economyt, whilst at the same time being consistent with the observation that, at the individual level, higher wealth is associated with greater absolute money holdings but lower money holdings relative to total wealth.

Third, the model incorporates as part of the solution households' rational portfolio response to the inflation risk that they face. As far as we are aware, existing work on the effect of inflation on welfare in heterogenous-agent models has focused either on the impact of mean inflation or unexpected shocks to inflation, leaving aside (by construction) households portfolio response to the expectation of future shocks. ${ }^{5}$ This dimension is crucial in the present study for at least two reasons. First, households are likely to respond ex ante to the inflation risk they are facing, i.e., we expect different levels of inflation risk to generate different mean holdings of nominal assets; and second, allowing significant redistributive effects of inflation (as the evidence suggests they are) but ignoring the ex ante portfolio response to inflation risk is likely to overestimate the welfare cost of inflation shocks.

The model features both aggregate (inflation) and idiosyncratic (labor productivity) shocks and is calibrated accordingly. Regarding the time-series dimension, we feed the model with an exogenous process for the money growth rate so that the equilibrium response of inflation matches the volatility properties of actual inflation over the post-Volcker, pre-Great Recession period. Treating equilibrium inflation (rather than the money supply) as the forcing term in our analysis ensures that the inflation risk that households face in the model is consistent with the historical inflation

\footnotetext{
${ }^{5}$ Imrohoroglu (1992) and Erosa and Ventura (2002) study the impact of mean inflation on welfare in incompletemarket environments. Cao et al. (2012) examine the redistributive and welfare effects of changes in mean inflation within an overlapping generations model. Similarly, Doepke and Schneider (2006a, 2006b) attempt to evaluate the redistributive and welfare effects of a moderate but persistent inflation episode in the US economy. They find these effects to be large, due to the significant degre of heterogeneity in nominal asset positions across US households and the large fraction of foreign holders of US assets. In the same spirit, Sterk and Teynero (2014) use an overlappinggeneration model to evaluate the impact of open market operations on durables consumption.
} 
risk. ${ }^{6}$ Concerning the cross-sectional dimension, we calibrate the wage income process as well as household's preferences towards money and consumption goods so as to match the joint crosssectional distributions of monetary and nonmonetary assets. Our analysis can thus be interpreted as way to discipline preferences towards money and goods on the basis of the statistical moments of cross-sectional data on monetary positions.

To evaluate the cost of inflation fluctuations and the way it is distributed across households, we compute the ex ante welfare of an agent conditional on a particular idiosyncratic state and portfolio, in economies with and without inflation risk. To summarize, we find significant welfare costs of inflation fluctuations for all households except for those at the top end of the productivity scale and/or the wealth distribution. For example, for a low-productivity household holding the average portfolio of the households with similar productivity (where the "average" is computed from the invariant distribution of the economy with aggregate risk), full elimination of inflation risk is equivalent to a 1.5 percent increase in lifetime consumption. We find similar welfare costs for intermediate productivity households starting with either the portfolio of the average household with similar productivity or the average portfolio of low-productivity households. While inflation risk generates no welfare loss (or even a small benefit) for households at the top of the productivity and/or wealth distribution, it generates an equivalent fall in permanent consumption for the "average" household that is close to 1 percent. Such welfare losses are large: they are one order of magnitude larger than those computed by Lucas $(1987,2003)$ in a representative-agent context $;^{7}$ and about five times the welfare cost of the business cycle as computed by Imrohoroglu (1989) within a nonmonetary incomplete-market, heterogenous-agent model. The magnitude of the welfare costs that we find is similar to that obtained in (nonmonetary) models with incomplete insurance wherein the extent of idiosyncratic risk is systematically related to the size of aggregate productivity shocks, a channel that is absent from our model. ${ }^{8}$

\footnotetext{
${ }^{6}$ Technically, we first estimate a two-state Markov process for inflation and then impose the constraint that the inflation series generated by our model be consistent with the estimated process. We can then recover the underlying process for money growth that has generated the equilibrium response of inflation. Calibrating a two state Markov process for money growth rather than would result in inflation overshooting following regime changes and would thereby overestimate actual inflation risk.

${ }^{7}$ Lucas' calculations only rely on the assumption of complete market and a specification for the representative agent's preferences. While maintaining complete markets and suitably chosing preferences can generate large welfare costs of the business cycle, Ostrok (2001) shows that this argument does not survive in general equilibrium wherein households optimally choose (and effectively smooth) consumption.

${ }^{8}$ See, e.g., Storsletten et. al. (2001) and Krusell et al. (2009).
} 
The rest of the paper is organised as follows. Section 2 presents the model, paying specific attention to the preference specification that underlies our analysis and its implications for the joint cross-sectional distribution of consumption and money. Section 3 discuss our parameterization. Section 4 presents our main results on the welfare costs of inflation fluctuations. Section 5 concludes.

\section{The model}

The model is a MIU, heterogenous-agent model of the type analysed by Algan and Ragot (2010), to which it adds i) aggregate inflation shocks (driven by underlying changes in money growth), and ii) a utility functional designed to accomodate a large amount of cross-sectional dispersion in money wealth.

\section{$2.1 \quad$ Preferences}

Households are infinitely-lived and in constant mass equal to 1. They share identical and additively time-separable preferences over sequences of consumption, $c \equiv\left\{c_{t}\right\}_{t=0}^{\infty}$, and real money balances, $m \equiv\left\{m_{t}\right\}_{t=0}^{\infty}$. Thus, they maximize

$$
U(c, m)=\mathbb{E}_{0} \sum_{t=0}^{\infty} \beta^{t} u\left(c_{t}, m_{t}\right),
$$

where $\beta \in(0,1)$ is the subjective discount factor, $\mathbb{E}_{t}$ denotes expectations conditional on the information set at date $t$, and $u$ is the instant utility function. Ths function is assumed to take the following parametric form:

$$
u\left(c_{t}, m_{t}\right)=\frac{1}{1-\lambda}\left(\omega c_{t}^{1-\rho}+(1-\omega) m_{t}^{\theta(1-\rho)}\right)^{\frac{1-\lambda}{1-\rho}} \cdot \rho, \theta, \lambda>0
$$

When $\theta=1$, (??) becomes a standard homothetic utility function similar to that used by Chari et al. (1996, 2000) and Algan and Ragot (2010), among others. In this case, the interest-rate elasticity of real money demand is $1 / \rho$, while the intertemporal elasticity of substitution between consumption and real balances is $(1-\rho) /(\lambda-\rho)$. As discussed above, an important limitation of the homothethic specification is that it implies a strict proportionality between individual real money holdings and individual consumption levels (for any given values of the nominal interest rate and the inflation rate). This makes it impossible to reproduce the highly unequal distribution of money holdings that is observed in US data. Our baseline calibration will thus have $\theta \neq 1$. 


\subsection{Idiosyncratic uncertainty}

In every period, households are subject to idiosyncratic labor income shocks. Labor productivity can take three different values $e_{t} \in E, E=\left\{e^{l}, e^{m}, e^{h}\right\}$ with $e^{l}<e^{m}<e^{h}$ and where $e^{h}$ stands for 'high productivity', $e^{m}$ for 'medium productivity', and $e^{l}$ for 'low productivity'. Each household's productivity evolves according to a first-order Markov chain with the $3 \times 3$ transition matrix $F$. We denote by $p^{*}$ the vector of stationary ergodic probabilities and normalize productivity levels so that the mean of the invariant distribution is one, i.e., $\sum p_{i}^{*} e_{i}=1$. Given a population of measure one, we can interpret $p^{*}$ as describing the distribution of the population across productivity states. It follows that the effective aggregate labor supply is equal to $\sum p_{i}^{*} e_{i} \bar{n}=\bar{n}$, where $\bar{n}$ stands for labour hours per period.

\subsection{Production technology}

Markets are competitive. In every period $t$, the representative firm uses aggregate capital $K_{t} \in \mathbb{R}_{+}$ and households' labor to produce $Y_{t} \in \mathbb{R}_{+}$units of a single good with the aggregate technology

$$
Y_{t}=f\left(K_{t}, \bar{n}\right)=K_{t}^{\alpha} \bar{n}^{1-\alpha}
$$

Capital depreciates at the constant rate $\delta \in(0,1)$ and accumulates according to the law of motion

$$
K_{t+1}=I_{t}+(1-\delta) K_{t}
$$

where $I_{t}$ denotes aggregate investment. Perfect competition in the markets for the representative firm's inputs implies that the real interest rate, $r_{t}$, and the real wage, $w_{t}$, are given by:

$$
r_{t}=\alpha K_{t}^{\alpha-1} \bar{n}^{1-\alpha}-\delta, w_{t}=(1-\alpha) K_{t}^{\alpha} \bar{n}^{-\alpha}
$$

\subsection{The household's problem}

We assume that markets are incomplete, so that households cannot write insurance contracts contingent on their labor income. Moreover, they face borrowing constraints and are thus prevented from using private loans to fully smooth out individual income fluctuations. Each household $i$ maximizes its expected lifetime utility (??) subject to the following constraints:

$$
\begin{gathered}
c_{t}^{i}+k_{t+1}^{i}+m_{t}^{i}=a_{t}^{i}+\left(1-\tau_{t}^{l}\right) w_{t} e_{t}^{i} \bar{n} \\
k_{t+1}^{i} \geq 0, m_{t}^{i} \geq 0, \text { and } c_{t}^{i} \geq 0,
\end{gathered}
$$


where $k_{t+1}^{i}$ and $m_{t}^{i}$ denote the claims to the capital stock and the real money balances held by household $i$ at the end of date $t$, and where

$$
a_{t}^{i}=\left(1+\left(1-\tau_{t}^{c}\right) r_{t}\right) k_{t}^{i}+\frac{m_{t-1}^{i}}{1+\pi_{t}}
$$

is the household's financial wealth at the beginning of date $t$. In (??) and (??), $\tau_{t}^{l}$ and $\tau_{t}^{c}$ are proportional taxes on labor and capital, respectively. In (??), the presence of the borrowing constraint is reflected in the fact that capital and money holdings must be nonnegative at all times, while no other assets (i.e., private bonds) can be issued by the households.

From the households' objective and constraints, we find that their optimal asset demands, $m_{t}^{i}$ and $k_{t+1}^{i}$, must satisfy the following first-order conditions:

- Money:

$$
u_{c}\left(c_{t}^{i}, m_{t}^{i}\right)-u_{m}\left(c_{t}^{i}, m_{t}^{i}\right)=\beta E_{t}\left[\frac{u_{c}\left(c_{t+1}^{i}, m_{t+1}^{i}\right)}{1+\pi_{t+1}}\right]
$$

- Capital:

$$
\begin{aligned}
\text { Either } u_{c}\left(c_{t}^{i}, m_{t}^{i}\right) & =\beta E_{t}\left[\left(1+\left(1-\tau_{t}^{c}\right) r_{t+1}\right) u_{c}\left(c_{t+1}^{i}, m_{t+1}^{i}\right)\right] \text { and } k_{t+1}^{i}>0, \\
& \text { or } u_{c}\left(c_{t}^{i}, m_{t}^{i}\right)>\beta E_{t}\left[\left(1+\left(1-\tau_{t}^{c}\right) r_{t+1}\right) u_{c}\left(c_{t+1}^{i}, m_{t+1}^{i}\right)\right] \text { and } k_{t+1}^{i}=0 .
\end{aligned}
$$

The instant utility function (??) implies that $u_{m}\left(c_{t}^{i}, 0\right)=\infty$, so the demand for real balances is always interior. In contrast, the demand for capital may be corner (i.e., $k_{t+1}^{i}=0$ ), in which case the household would like to raise current consumption by borrowing against future income but is prevented from doing so by a binding borrowing constraint. The solution to the households' problem provides sequences of functions $m_{t}(a, e), k_{t}(a, e)$ and $c_{t}(a, e),(a, e) \in \mathbb{R}_{+} \times\left\{e_{1}, e_{2}, e_{3}\right\}$, where $a$ and $e$ denote individual beginning-of-period asset wealth and productivity, respectively.

To better understand the implications of our assumed period utility function with non-constant elasticity of substitution (i.e., (??)), consider the optimal trade-off between consumption and real money holdings by an unconstrained household (so that $k_{t+1}^{i}>0$ in (??)) and abstract from aggregate shocks momentarily. From (??)-(??), we find the relation between money holdings and consumption to be:

$$
m_{t}^{i}=A\left(\left(1-\tau_{t}^{c}\right) r_{t+1}, \pi_{t+1}\right)\left(c_{t}^{i}\right)^{\frac{\rho}{1-\theta(1-\rho)}}
$$


where $A\left(\left(1-\tau_{t}^{c}\right) r_{t+1}, \pi_{t+1}\right)$ is a coefficient whose value depends on the returns on the two assets and the deep parameters of the utility function. In the constant-elasticity case (i.e., $\theta=1$ ), we have $m_{t}^{i}=A\left(\left(1-\tau_{t}^{c}\right) r_{t+1}, \pi_{t+1}\right) c_{t}^{i}$, that is, real money demand is strictly proportional to consumption, so that cross-sectional inequalities in these two variables mirror each other. For individual money holdings to increase more than proportionally following an increase in individual consumption, so that money be more unequally distributed than consumption (as is observed in the data), one needs $\rho /(1-\theta(1-\rho))>1$ (whether $\theta$ must lie above or below 1 for this inequality to hold depends on the value of $\rho$.)

\subsection{Market clearing}

Define $\mu_{t}: \mathbb{R}_{+} \times\left\{e^{h}, e^{m}, e^{l}\right\} \rightarrow \mathbb{R}_{+}$as the joint cross-sectional distribution of wealth and individual productivity at the beginning of period $t$. The market-clearing conditions for real balances and capital claims are given by:

$$
\int m_{t}^{i}\left(a_{t}, e_{t}\right) d \mu\left(a_{t}, e_{t}\right)=\Omega_{t}^{s}
$$

and

$$
\int k_{t}\left(a_{t}, e_{t}\right) d \mu\left(a_{t}, e_{t}\right)=K_{t+1}
$$

where $\Omega_{t}^{s}$ the total quantity of real balances at date $t$. By Walras law, the goods market clear when both the money and the capital markets clear.

\subsection{Fiscal and monetary policy}

Fiscal and monetary policies interact here because monetary policy generates segniorage revenues that determine government income jointly with tax collections. We specify both as follows.

First, we assume that inflation follows a two-state Markov chain: the inflation rate transit between $\pi^{L}$ and $\pi^{H}>\pi^{L}$ according to the transition matrix $T$. Since inflation is endogenously determined in equilibrium, we must reverse-ingeneer the process for the money growth rate that produces this inflation process as an equilibrium outcome. The two inflation levels as well as the transition probabilities between the two can then be calibrated according to historical data. This ensures that the amount of inflation risk faced by the households in the model is consistent with its historical counterpart. ${ }^{9}$

\footnotetext{
${ }^{9}$ Feeding the model with a two-state Markov chain for the money growth rate instead of the inflation rate generates inflation overshooting following regime changes. This specification would greatly misrepresent historical inflation risk.
} 
For a given inflation process, the growth rate of the quantity of money $\gamma_{t}$ is determined as follows. Let $\Delta_{t}$ denote the quantity of newly issued money at date $t$ (relative to the stock of money at the end of date $t-1)$ and by $\Pi_{t}=P_{t} / P_{t-1}=1+\pi_{t} \in\left\{\Pi^{L}, \Pi^{H}\right\}$ the gross inflation rate between date $t-1$ and date $t$. In real term, the quantity of newly issued money can be expressed as:

$$
\Delta_{t} / P_{t}=\gamma_{t} P_{t-1} \Omega_{t-1}^{s} / P_{t}=\gamma_{t} \Omega_{t-1}^{s} / \Pi_{t}
$$

and the dynamics of total real money balances by:

$$
\Omega_{t}^{s}=\left(1+\gamma_{t}\right) \Omega_{t-1}^{s} / \Pi_{t}
$$

Given $\Omega_{t-1}^{s}$ and current gross inflation $\Pi_{t}\left(\in\left\{\Pi^{L}, \Pi^{H}\right\}\right)$ we determine $\gamma_{t}$ so that $\Omega_{t}^{s}$ clears the money market (i.e., so that (??) holds) given aggregate money demand (which is a function of the aggregate state including $\Pi_{t}$, but not of $\gamma_{t}$ ).

We assume for simplicity that the budget is balanced in every period. The government budget constaint is thus given by:

$$
G_{t}=\gamma_{t} \Omega_{t-1}^{s} / \Pi_{t}+\tau_{t}^{l} w_{t} \bar{n}+\tau_{t}^{c} r_{t} K_{t}
$$

We assume that $G_{t}=G>0$ is constant over time and then let the tax rates on capital and labor adjust to satisfy the government budget constraint in every period. This ensures that inflation risk does not generate wealth effects "in the aggregate" (which would somewhat artificially amplify the welfare cost of inflation fluctuations). For simplicity we assume that the ratio of the two taxes $\psi=\tau_{t}^{c} / \tau_{t}^{l}$ is constant over time, so that the taxes on labor and capital are given by, respectively:

$$
\tau_{t}^{l}=\frac{G-\gamma_{t} \Omega_{t-1}^{s} / \Pi_{t}}{w_{t} L+\psi r_{t} K_{t}}, \tau_{t}^{c}=\psi \tau_{t}^{l}
$$

\subsection{Recursive problem and equilibrium}

We are considering a recursive equilibrium in which the aggregate state, which includes the aggregate stock of capital, changes over time. Note that the way we have specified monetary policy implies that households need not keep track of the aggregate money supply, because inflation (the inverse of the return on money holdings) enters as an exogenous forcing term here (with the rate of money growth adjusting to make a particular inflation path happen). It follows that the recursive problem of a household can be written as:

$$
v\left(a_{t}, e_{t} ; \pi_{t}, K_{t}\right)=\max _{m_{t}, c_{t}, k_{t+1}} u\left(c_{t}, m_{t}\right)+\beta E_{t}\left[v\left(a_{t+1}, e_{t+1} ; \pi_{t+1}, K_{t+1}\right) \mid e_{t}, \pi_{t}\right],
$$


subject to (??)-(??). Following Krusell and Smith (1998) and much of the subsequent literature, we posit that households are able to successfully forecast the dynamics of the endogenous aggregate state $K_{t}$ by means of (log-) linear laws of motion (one per value of the exogenous aggregate state $\pi_{t}$ ) involving only the mean of $K_{t}$ :

$$
\ln \left(K_{t+1}\right)=b_{1}\left(\pi_{t}\right)+b_{2}\left(\pi_{t}\right) \ln \left(K_{t}\right)+b_{3}\left(\pi_{t}\right) \ln \left(\Omega_{t}^{s}\right)
$$

The solution to (??) produces individual decision rules for consumption as well as holdings of real balances and claims to the capital stock, which we denote by $g_{c}\left(a_{t}, e_{t} ; \pi_{t}, K_{t}\right), g_{m}\left(a_{t}, e_{t} ; \pi_{t}, K_{t}\right)$ and $g_{k}\left(a_{t}, e_{t} ; \pi_{t}, K_{t}\right)$, respectively. The law of motion of the distribution for beginning-of period total wealth is denoted by $H$. For a given set of individual policy rules, this law of motion can be written as

$$
\mu_{t}=H\left(\mu_{t-1}, \pi_{t}\right)
$$

i.e., the cross-sectional distribution of wealth $\mu_{t}$ depends on its value in the previous period $\mu_{t}$ as well as the current realization of the exogenous aggregate state $\pi_{t}$.

Definition of the recursive equilibrium. A recursive equilibrium is defined by a law of motion $H$, a set of optimal individual policy and value functions $\left\{g_{c}, g_{m}, g_{k}, v\right\}$, a set of price functions $\{\pi, r, w\}$, and a set of law of motion for $K$ such that:

1. Given $\{\pi, r, w\}$, the law of motion for $K_{t}$ and the transition matrices $F$ and $T$, the policy functions $\left\{g_{c}, g_{m}, g_{k}\right\}$ solve the household's problem;

2. The money and capital markets clear;

3. The law of motion of $H$ is generated by the optimal decisions $\left\{g_{c}, g_{m}, g_{k}\right\}$, and the transition matrices $F$ and $T$.

We solve for the recursive equilibrium using the same approach as in Krusell and Smith (1997, 1998). However, rather than using Monte Carlo simulations to generate an updated cross-sectional distribution, we use the grid-based simulation procedure proposed by Young (2010), which keeps track of the mass of households at a fine grid of wealth levels. This allows us to get rid of the crosssectional sampling variations in the Monte Carlo simulation procedure. A detailed description of the algorithm is provided in the Appendix. 


\section{Parameterization}

Table 1: Parameter values and simulation targets common across economies

\begin{tabular}{llllll}
\hline \multicolumn{5}{c}{ Parameter set outside the model } & \\
Preferences & $\lambda$ & 1.00 & Production & $\alpha$ & 0.360 \\
& $\beta$ & 0.99 & & $\delta$ & 0.025 \\
& $\rho$ & 20.00 & & $\bar{n}$ & 0.300 \\
$\omega$ & 0.06 & & & \\
& $\theta$ & 0.21 & & \\
Productivity & $e^{l}$ & 3.940 & & \\
& $e^{m}$ & 0.849 & & \\
& $e^{h}$ & 0.213 & & \\
& $\pi_{l, l}$ & 0.975 & & \\
& $\pi_{m, m}$ & 0.992 & & \\
\hline
\end{tabular}

Table ?? reports the parameters of the model. The time period is a quarter. Following Chari et al. (2000), our benchmark value for the utility parameter $\lambda$ is 1 . The capital share is set to $\alpha=0.36$, and the depreciation rate to 0.025. Finally, labor supply is constant for all households and set to 0.3. ${ }^{10}$ The individual productivity states and the transition probabilities across states are calibrated as follows. Following Domjei and Heathcote (2004), we use a Markov chain with three states, zero probabilities to transit between extreme states (i.e., $F_{h, l}=F_{l, h}=0$ ), and an equal probability to reach any of the extreme states when in the intermediate state (i.e., $F_{m, h}=F_{m, l}$ ). The transition matrix is then fully identified once $F_{l, l}, F_{m, m}$ and $F_{h, h}$ are set, and we set $F_{l, l}=F_{h, h}=0.9750$, $F_{m, m}=0.9925$. Finally, the ratios of productivity are set to $e^{h} / e^{m}=4.64$ and $e^{m} / e^{l}=3.99$. This process yields an autocorrelation of the real wage equal to 0.91 and a standard deviation of the innovation term equal to 0.22 at annual frequency, in line with the data.

Table ?? also provides the preference parameters that best match key targets such as the Gini of the money distribution; the money to GDP ratio; the interest rate elasticity of money; and the capital-output ratio. The monetary aggregate that we consider is M2, which best corresponds to the notion of "liquid assets" in the Survey of Consumer Finances. Note that the Gini coefficient of this distribution is as high as 0.85. The quartely value of M2 over GDP over the 1982-2005 period is 0.52 .

We model the dynamics of monetary conditions between 1982Q1 and 2005Q4 as a two-state,

\footnotetext{
${ }^{10}$ It is straightforward to introduce elastic labor supply using GHH preferences, as in Heathcote (2005).
} 
first-order Markov chain. More specifically, we estimate this chain using CPI-inflation and extract the inflation levels that prevail in the 'high-'versus 'low-inflation'regimes, as well as the probabilities to transit between those regimes. This gives $\pi^{L}=0.64 \%, \pi^{H}=1.17 \%$, and probabilities to stay in the same state $\operatorname{Pr}\left(\pi^{L} \mid \pi^{L}\right)=0.944$ and $\operatorname{Pr}\left(\pi^{H} \mid \pi^{H}\right)=0.889$.

We specify the fiscal policy parameters $G$ and $\psi$ as follows. According to Domeij and Heathcote (2004), for the period 1990-1996 the capital income tax rate averaged 39.7 percent, while the labor income tax rate averaged 26.9 percent. We thus set $\psi=39.7 / 26.9$. Moreover, applying those rates to a version of our model without aggregate risk (and with inflation equal to the unconditional mean of inflation in the baseline model) gives $G=0.25$ as a residual; we thus calibrate $G$ to this value in the baseline economy.

\section{Results}

\subsection{Equilibrium distributions and laws of motion}

We first check that our calibration does reproduces the broad features of the US wealth distribution. Unlike earlier studies, we seek to match the distributions of two components of total wealth: money wealth and nonmonetary wealth. Given our focus on the portfolio structure chosen by the households, our empirical counterparts from the Survey of Consumer Finances (SCF 2004) are the following. First, we use the "liquid assets" component of financial wealth as a measure of households' money wealth (as argued above, this roughly corresponds to the assets belonging to the M2 monetary aggregate). Liquid assets in the SCF are essentially made of money market accounts, checking accounts, saving accounts and call accounts. Second, we compute the distribution of nonmonetary wealth by removing liquid assets from the financial assets held by the households in the SCF. From the SCF, nonmonetary wealth refers to bonds, stocks, life insurance, retirement plans and other managed financial assets. Table ?? compares the properties of those two distributions with those generated by the model, under the parameter configuration specified in Tables ??-??.

Given our parametric utility function, all households hold some money in our model, even though the amount being held may be very small. However, many households are not wealthy enough to hold both money and nonmonetary assets: they are "constrained", in the sense of endogenously choosing not to hold capital -not in the sense of holding zero wealth.

The benchmark model predicts a fairly high Gini index for the distribution of nonmonetary 
assets (0.81), as is consistent with the data (0.82). Moreover, the model does a reasonable job in matching the lower tail of the distribution of nonmonetary assets. Perhaps unsurprisingly, the model underestimates the nonmonetary wealth share of the top $1 \%$, which is predicted to be $9.03 \%$ while it is $34.30 \%$ in the data. This flaw is common to many models that only use idiosyncratic income risk to generate wealth dispersion and ignore, for example, entrepreneurship (see, e.g., Quadrini, 2000.)

Our model predicts that $6.6 \%$ of the households on average face a binding borrowing limit. The range of available estimates for this share is notoriously large. Using information on the number of borrowing requests which were rejected in the SCF, Jappelli argued that up to $19 \%$ of families are liquidity-constrained. However, using updated SCF data, Budria Rodriguez et al. (2002) reported that only $2.5 \%$ of the households have zero wealth, which might better correspond to our theoretical borrowing limit.

Finally, we find the following laws of evolution for capital:

$$
\begin{aligned}
\text { low inflation } & : \ln K_{t+1}=0.4723+0.7870 \ln K_{t}+0.1140 \ln \Omega_{t}^{s}, R^{2}=0.9982 . \\
\text { high inflation } & : \ln K_{t+1}=0.4421+0.8085 \ln K_{t}+0.1155 \ln \Omega_{t}^{s}, R^{2}=0.9981
\end{aligned}
$$

As in Krusell and and Smith (1998), we find the first-order moments of the distributions to yield an almost perfect prediction of prices (based on the R-square statistics.)

\subsection{Individual policy rules}

Figure 1 displays the individual policy rules when the money growth rate is $\pi^{L}$ (the policy rules when $\pi=\pi^{H}$ have a very similar shape) and for the average levels of capital. The policy rules for total wealth, nonmonetary assets, money and consumption are decomposed for each level of productivity $e^{h}, e^{m}$ and $e^{l}$. For example, the third panel of Figure 1 reports the individual policy rules for nonmonetary assets. The policy rule lies above the 45-degree line for the most productive household (with productivity $e^{h}$ ) and below the 45-degree line for the other two types (with productivity $e^{m}$ or $e^{l}$ ). This implies that the former accumulate nonmonetary assets for self-insurance purposes whereas the latter dis-save to smooth individual consumption. For medium- and low-productivity households, the policy rule displays a kink at low levels of wealth; this is because at such wealth levels these households hold money but no nonmonetary assets. The second and fourth panels show 
Table 2: Wealth distribution

\begin{tabular}{lcc}
\hline \multicolumn{2}{l}{ Distribution of nonmonetary assets } & Economy* \\
Gini & 0.82 & 0.81 \\
Share of constrained households & {$[2 \%, 20 \%]$} & $6.6 \%$ \\
Fraction of total asset held by & & \\
$\quad$ Bottom 20\% & 0.00 & 0.12 \\
$\quad$ Bottom 40\% & 0.20 & 0.26 \\
$\quad$ Top 20\% & 84.70 & 78.22 \\
$\quad$ Top 10\% & 71.20 & 52.89 \\
$\quad$ Top 1\% & 34.30 & 9.03 \\
Distribution of money holdings & & \\
Gini & 0.85 & 0.81 \\
Fraction of total money held by & & \\
$\quad$ Bottom 20\% & 0.00 & 0.84 \\
$\quad$ Bottom 40\% & 0.00 & 1.66 \\
$\quad$ Top 20\% & 88.20 & 87.69 \\
$\quad$ Top 10\% & 76.46 & 67.34 \\
$\quad$ Top 1\% & 39.49 & 15.55 \\
$\quad$ & \\
Capital/GDP & 12.00 & 10.37 \\
Money/GDP & 0.52 & 0.32 \\
\hline
\end{tabular}

* The model properties are averages over a 10,000 period simulation.

the policy rules for money holdings and consumption, which roughly display the same pattern as the policy rule for nonmonetary assets. The more productive the household (holding wealth constant), or the wealthier the household (holding productivity constant), the higher are individual consumption and money holdings. The close connection between the policy rules for consumption and money holdings stems from the complementarity between the two, a direct implication of our assumed instant utility function. 


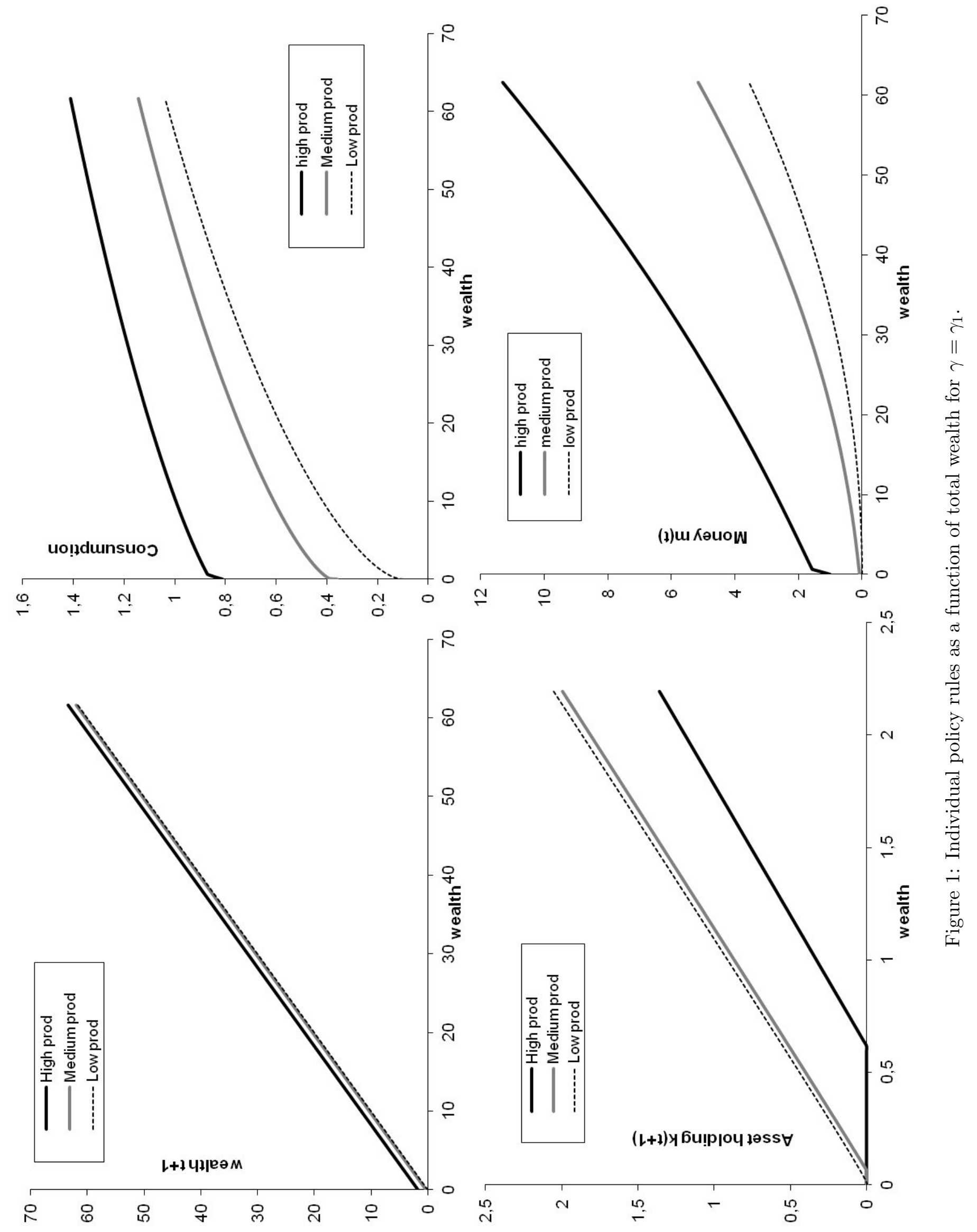




\subsection{Welfare}

We now evaluate the welfare cost of inflation fluctuations within our incomplete-market economy. We do so by performing ex ante welfare comparison conditional on a particular value of the individual state vector (productivity and wealth). The benchmark that we use for comparision is an economy without inflation risk, where the inflation rate is constant and equal to the unconditional mean of inflation in the baseline model with inflation risk. We wish to understand who are the the losers (or winners) from fluctuating inflation and thus proceed as follows.

First, we compute the ergodic distribution of households over productivity $e$ and beginning-ofperiod wealth $a$ generated by our baseline model, and extract from it the average beginning-ofperiod wealth over all households (denoted by $\bar{a}$ ) as well as the corresponding averages for low-, medium- and high-productivity levels (denoted by $a^{l}, a^{m}$ and $a^{h}$, respectively).

Second, we compute the ex ante welfare of typical households in the baseline economy. For example, to compute the ex ante welfare of a low-productivity (i.e., $e^{l}$ ) household, we first compute his ex post intertemporal welfare $\left(\sum_{t=0}^{\infty} \beta^{t} u\left(c_{t}, m_{t}\right)\right)$ under a particular history of idiosyncratic and aggregate shocks after date 0 (with transition probabilities $F$ and $T$ ), letting him start his life with the average portfolio of households with similar productivity (i.e., $a^{l}$ ). We then repeat the same computation for ten thousand productivity histories, but under the same initial condition and history of aggregate shocks. Averaging over all idiosyncratic histories then gives use the ex ante welfare of this typical household (i.e., $\mathbb{E}_{0} \sum_{t=0}^{\infty} \beta^{t} u\left(c_{t}, m_{t}\right)$ ). We perform similar conditional welfare computations for the typical medium- $\left(e^{m}, a^{m}\right)$ and high-productivity $\left(e^{h}, a^{h}\right)$ households. To broaden the picture, we also compute the ex ante welfare of medium-productivity households $\left(e^{m}\right)$ starting his life with the typical portfolio of a high- or a low-productivity household (ie. $a^{l}$ or $\left.a^{m}\right)$. This would be the ex ante welfare level of a household who would have just transited into the medium-productivity class, after having stayed highly (or little) productive for a while. We also compute the ex ante welfare levels by initial productivity types for households starting their life with the economywide average beginning-of-period wealth $\bar{a}$.

Third, we run exactly the same conditional, ex ante welfare computations in the benchmark economy without aggregate inflation shocks, wherein inflation stays constant at the unconditional mean inflation rate of the baseline model (with individual welfare levels computed using the same 
individual histories as in the economy with inflation risk). The welfare cost of inflation fluctuations for a particular household type is then the difference in ex ante welfare for this type (i.e., holding initial productivity and wealth the same) between the two economies. In table 3 we report the welfare costs of inflation for the various household types under considerations, expressing welfare costs in terms of equivalent life-time proportional consumption loss. For example, for a currently mid-productivity household $\left(e^{m}\right)$ holding the typical portfolio of this category $\left(a^{m}\right)$, switching from the constant-inflation benchmark to an economy with inflation risk is as costly as staying in the constant inflation economy but experiencing a permanent 1.23 percent drop in individual consumption.

\begin{tabular}{lll} 
Productivity & Initial wealth & Welfare cost (\% of permanent consumption) \\
\hline$e^{h}$ & $a^{h}$ & -0.36 \\
$e^{m}$ & $a^{h}$ & -0.80 \\
$e^{m}$ & $a^{m}$ & 1.23 \\
$e^{m}$ & $a^{l}$ & 1.77 \\
$e^{l}$ & $a^{l}$ & 1.24 \\
$e^{h}$ & $\bar{a}$ & 0.87 \\
$e^{m}$ & $\bar{a}$ & 0.89 \\
$e^{l}$ & $\bar{a}$ & 0.93 \\
\hline
\end{tabular}

Differentiating households by productivity types only - that is, considering the welfare loss of individuals with different beginning-of-life productivity - but holding the same initial wealth the economywide average $\bar{a}$ - illustrates the fact that on average individuals tend to suffer from inflation fluctuations, with an equivalent permanent consumption loss close to $1 \%$.

Importantly, the welfare cost of inflation fluctuations that we find are very unevenly distributed across households. In particular, while most households incur large welfare losses (up to 1.77\% of permanent consumption), the most productive and/or wealthy households incur no loss or even a gain. Such is the case both for the typical high-productivity individual (starting with the average wealth of individuals with same productivity, $a^{h}$ ) and for a medium-productivity household having been lucky enough in the past to have accumulated $a^{h}$. To understand why this is the case, one must bear in mind how inflation risk affects households' utility under our preference specification. More specifically, the impact of inflation risk on individual welfare can be traced back to two effects: a direct effect due to fluctuations in the marginal utility of money holdings, and an indirect effect working through the distribution of aggregate capital income across households. The first effect implies that inflation risk, which mechanically generates volatility in real money holdings, hurts 
all households holding cash (since utility is concave in real balances). The second effect is related to the complementarity between money and consumption. Because the marginal utility of real balances is concave and consumption and real balances are complement, an increase in the volatility of future real money balances (as implied by greater inflation risk) lowers the average marginal utility of future consumption and hence discourages current savings. ${ }^{11}$ This is true for all types of savings, including holdings of capital claims, and for all households, i.e., at all productivity levels. Hence, inflation risk lowers the capital stock and raises the return on capital claims, which tilts the distribution of total capital income towards high-productivity households (who holds greater capital holdings on average). ${ }^{12}$ The indirect effect turns out to (mildly) dominate the direct effect for high productivity or mid-prodictivity/high wealth households, causing them to benefit rather than suffer from inflation risk in equilibrium.

\section{Conclusion}

\section{TBC}

\footnotetext{
${ }^{11}$ Note that the lower future average marginal utility of consumption is accompanied by a greater volatility of future marginal utility of consumption. Since the marginal utility of consumption is convex at all levels of real balances, a "prudence" effect will limit, but not overturns, the impact of inflation risk on the average marginal utility of consumption (formally, the impact of prudence on current consumption-saving choices operates at one order of magnitude below the effect due to the complementarity between consumption and money).

${ }^{12}$ The quartely after-tax rates of return on capital claims are or average $0.60 \%$ and $0.59 \%$ in the high and the low inflation states of the baseline economy, respectively, while the same return is time-invariant at $0.55 \%$ in the economy without inflation risk.
} 


\section{References}

[1] Aiyagari, S. R., 1994. Uninsured idiosyncratic risk and aggregate saving, Quarterly Journal of Economics, 109(3), pp. 659-684.

[2] Akyol, A., 2004. Optimal monetary policy in an economy with incomplete markets and idiosyncratic risk, Journal of Monetary Economics, 51, pp. 1245-1269.

[3] Algan Y. and Ragot, X., 2010. Monetary policy with heterogeneous agents and borrowing constraints, Review of Economic Dynamics, 13(2), pp. 295-316.

[4] Algan Y., Challe, E. and Ragot, X., 2011. Incomplete markets and the output inflation tradeoff, Economic Theory, 46(1), pp. 55-84.

[5] Bewley, T., 1980. The optimum quantity of money, In: Kareken, J.H, Wallace, N., (Eds), Models of Monetary Economies.

[6] Berentsen, A., Camera, G. and Waller, C., 2005. The distribution of money balances and the nonneutrality of money, International Economic Review, 46(2), pp. 465-487.

[7] Budria Rodriguez, S., Diaz-Gimenez, J., Quadrini, V. and Rios-Rull, J.-V., 2002. Updated facts on the U.S. distributions of earnings, income, and wealth, Federal Reserve Bank of Minneapolis Quarterly Review, Summer, pages 2-35.

[8] Cao, S., Meh, C.A., Rios-Rull, J.-V. and Terajima, Y., 2012. Inflation, demand for liquidity, and welfare. Working Paper.

[9] Challe, E., Le Grand, F. and Ragot, X. (2013), Incomplete markets, liquidation risk, and the term structure of interest rates, Journal of Economic Theory, 148(6), pp. 1483-1519

[10] Chari, V.V., Christiano, L.J. and Kehoe, P.J., 1996. Optimality of the Friedman rule in economies with distorting taxes, Journal of Monetary Economics, 37(2), pp. 203-223.

[11] Chari, V.V., Kehoe, P.J. and McGrattan, E.R., 2000. Sticky-price models of the business cycle: Can the contract multiplier solve the persistence problem?, Econometrica, 68(5), pp. 1151-1179. 
[12] Cooley, T. (ed.), Frontiers of Business Cycle Research, Princeton University Press, 1995.

[13] Cooley, T., Hansen, G., 1989. The inflation tax in a real business cycle model, American Economic Review, 79(4), pp 733-48.

[14] Doepke, M. and Schneider, M., 2006. Inflation and the redistribution of wealth, Journal of Political Economy, 114(6), pp. 1069-1097.

[15] Domeij, D. and Heathcote, J., 2004. On the distributional effects of reducing capital taxes, International Economic Review, 45(2), pp. 523-554.

[16] Erosa, A. and Ventura, G., 2002. On inflation as a regressive consumption tax, Journal of Monetary Economics, 49, pp. 761-795.

[17] Friedman, M., 1968, The optimum quantity of money, in The Optimum Quantity of Money and Other Essays, Aldine Transactions, 2006.

[18] Heathcote, J., 2005. Fiscal policy with heterogenous agents and incomplete markets, Review of Economic Studies, 72(1), pp. 161-188.

[19] Heer, B. and Maussner, A. , 2011. The burden of unanticipated inflation: Analysis of an overlapping generations model with progressive income taxation and staggered prices, Macroeconomic Dynamics, forthcoming.

[20] Holman, J. A., 1998. GMM estimation of a money-in-the-utility-function model: The implications of functional forms, Journal of Money, Credit and Banking, 30(4), pp. 679-698.

[21] Huggett, M., 1993, The risk-free rate in heterogenous-agent incomplete-insurance economies, Journal of Economic Dynamics and Control, 17, pp. 953-69.

[22] Imrohoroglu, A., 1992. The welfare cost of inflation under imperfect insurance, Journal of Economic Dynamics and Control, 16, pp. 79-91.

[23] Imrohoroglu, A., 1989. The cost of busines cycles with indivisibilities and liquidity constraints, Journal of Political Economy, 97(6), pp. 1364-83.

[24] Jappelli, T., 1990. Who is credit constrained in the US Economy, Quarterly Journal of Economics, 105(1), pp. 219-234. 
[25] Kehoe, T.J., Levine, D.K., and Woodford, M., 1992. The optimum quantity of money revisited, in Economic Analysis of Markets and Games, ed. by Dasgupta, D. Gale, O. Hart, and E. Maskin, Cambridge, MA: MIT press, pp. 501-526.

[26] Krebs, T., 2003. Growth and welfare effects of business cycles in economies with idiosyncratic human capital risk, Review of Economic Dynamics, 6(4), pp. 846-868.

[27] Krusell, P., Mukoyama and Smith, A.A., 2011. Asset Prices in a Huggett Economy, Journal of Economic Theory, 146(3), pp. 812-844.

[28] Krusell, P., Mukoyama, T., Şahin, A. and Smith, A.A., 2009. Revisiting the welfare effects of eliminating business cycles, Review of Economic Dynamics, 12(3), pp. 393-402.

[29] Krusell, P., Smith, A.A., 1998. Income and wealth heterogeneity in the macroeconomy, Journal of Political Economy, 106(5), pp. 867-896.

[30] Krusell, P., Smith, A.A., 1997. Income and wealth heterogeneity, portfolio choice, and equilibrium asset returns, Macroeconomic Dynamics, 1, pp. 387-422.

[31] Lucas, R.E., 2003. Macroeconomic priorities, American Economic Review, 93, pp. 1-14.

[32] Lucas, R.E., 1987. Models of Business Cycles, Oxford University Press.

[33] Otrok, C., 2001. On measuring the welfare cost of business cycles, Journal of Monetary Economics, 47 (1), pp. 61-92

[34] Quadrini, V., 2000. Entrepreneurship, saving and social mobility, Review of Economics Dynamics, 3(1), pp. 1-40.

[35] Patinkin, D., 1956. Money, Interest and Prices, Row-Peterson.

[36] Ragot, X., 2014, The case for a financial approach to money demand, Journal of Monetary Economics, 62, pp. 94-107.

[37] Scheinkman, J.A. and Weiss, L., 1986. Borrowing constraints and aggregate economic activity, Econometrica, 54(1), pp. 23-45. 
[38] Sidrauski, M., 1967. Rational choice and patterns of growth in a monetary economy, American Economic Review, 57(2), pp. 534-544.

[39] Storesletten, K., Telmer, C. and Yaron, A., 2001. The welfare costs of business cycles revisited: Finite lives and cyclical variation in idiosyncratic risk, European Economic Review, 45 (7), pp. 1311-1339.

[40] Walsh, C., 2010, Monetary Theory and Policy, MIT Press, 3rd ed.

[41] Young, E., 2010. Solving the incomplete markets model with aggregate uncertainty using the Krusell-Smith algorithm and non-stochastic simulations, Journal of Economic Dynamics and Control, 34(1), pp 36-41.

\section{A Numerical Algorithm}

\section{A.1 Overview of the Algorithm}

The algorithm used to obtain the solution of the model is as follows.

1. Given laws of motion for real money balance and capital, defined by (??) and (??), solve the individual's problem given by the equations (??), (??), (??) and $k_{t+1}>0$.

2. Simulate the economy to approximate the equilibrium laws of motion for $K$ and $M$. We use the grid-based simulation procedure proposed by Young (2010).

(a) Set an initial wealth/employment-efficiency distribution $\mu_{0}(a, e)$ that provides $p_{0}^{i, e}$ the mass of agents of employment-efficiency type $e$ with wealth $a_{i}$ at the $i$ th wealth grid point for $i=1, \cdots, N_{\text {grid }}$; an initial value for $\pi$; and initial individual policy rules for $k$ and $m \cdot .^{13}$

(b) Given the decision rules $g_{k}\left(a_{t}, e_{t} ; \pi_{t}, K_{t}\right)$, and $g_{m}\left(a_{t}, e_{t} ; \pi_{t}, K_{t}\right)$ that solve the individual's problem, the wealth/employment-efficiency distribution $\mu\left(a_{t}, e_{t}\right)$, and a draw for $\pi_{t}$, calculate

$$
\int g_{m}\left(a_{t}, e_{t} ; \pi_{t}, K_{t}\right) d \mu\left(a_{t}, e_{t}\right)=M_{t}
$$

\footnotetext{
${ }^{13}$ We use the wealth distribution and the associated policy rules that we get for the economy without monetary shock.
} 
and

$$
\int g_{k}\left(a_{t}, e_{t} ; \pi_{t}, K_{t}\right) d \mu\left(a_{t}, e_{t}\right)=K_{t+1}
$$

c. Repeat steps (b) and (c) and obtain a long time series for $K$ and $M$, of which the first part is discarded.

3. Use the time series obtained in step (2) to get the new equilibrium laws of motion for $K$ and $M$.

4. Compare the new equilibrium laws of motion for $K$ and $M$ with those used in step (1). If they are similar, stop. Otherwise, update the coefficients of the laws of motion, and go to step (1).

\section{A.2 Details on the Resolution of the Individual Problem}

We have the following first order conditions

$$
\begin{gathered}
u_{c}\left(c_{t}, m_{t}\right)-u_{m}\left(c_{t}, m_{t}\right)=\beta E_{t}\left[\frac{v_{a}\left(a_{t+1}, e_{t+1} ; \pi_{t+1}, K_{t+1}\right)}{1+\pi_{t+1}}\right] \\
u_{c}\left(c_{t}, m_{t}\right)=\beta E_{t}\left[\left(1+\left(1-\tau_{t+1}^{c}\right) r_{t+1}\right) v_{a}\left(a_{t+1}, e_{t+1} ; \pi_{t+1}, K_{t+1}\right)\right]
\end{gathered}
$$

The last equation is true if $k_{t+1}>0$. Given an initial guess for $v_{a}^{0}($.$) , the first derivative with$ respect to $a$ of the value function, for each grid point, we will solve the individual problem defined by the previous FOC and the budget constraint (??). Given the solution at each grid point, we get a new $v_{a}^{1}()=.u_{c}\left(c_{t}, m_{t}\right)$. If the new derivative of the value function is close to the old one, we have found an approximation of the fixed point, and we get $g_{c}^{0}(),. g_{k}^{0}($.$) , and g_{m}^{0}($.$) as the solution$ of the problem. If not, we update $v_{a}^{0}()=.v_{a}^{1}($.$) .$

We have two distinct cases:

1) If $k_{t+1}=0$, we solve the non linear equation in $m_{t}$ :

$$
u_{c}\left(c_{t}, m_{t}\right)-u_{m}\left(c_{t}, m_{t}\right)-\beta E_{t}\left[\frac{v_{a}^{0}\left(a_{t+1}, e_{t+1} ; \pi_{t+1}, K_{t+1}\right)}{1+\pi_{t+1}}\right]=0
$$

where $c_{t}=a_{t}+\left(1-\tau_{t}^{l}\right) w_{t} e_{t} \bar{n}-m_{t}$, and given $v_{a}^{0}\left(a_{t+1}, e_{t+1} ; \pi_{t+1}, K_{t+1}\right)$ where $a_{t+1}=\frac{m_{t}}{1+\pi_{t+1}}$, and $K_{t+1}$ given by the fixed aggregate laws of motion. 
2) If $k_{t+1}>0$, we find the solution for $g_{c}, g_{m}, g_{k}$, and $v_{a}$ using nested bisection methods. First, we solve for $m$ and $k$ given a certain level of consumption using equation (??) and the budget constraint. Second, we solve the capital foc for $c$ where the $m$ and $k$ are given by the previous step. More formally, for each grid point, we have the following steps:

1. For a given value of $c$, solve the following foc for $m$

$$
u_{c}\left(c_{t}, m_{t}\right)-u_{m}\left(c_{t}, m_{t}\right)-\beta E_{t}\left[\frac{v_{a}^{0}\left(a_{t+1}, e_{t+1} ; \pi_{t+1}, K_{t+1}\right)}{1+\pi_{t+1}}\right]=0
$$

given $v_{a}^{0}\left(a_{t+1}, e_{t+1} ; \pi_{t+1}, K_{t+1}\right)$ where $a_{t+1}=\left(1+\left(1-\tau_{t+1}^{c}\right) r_{t+1}\right) k_{t+1}+\frac{m_{t}}{1+\pi_{t+1}}$, and $k_{t+1}$ deduced from the budget constraint. $K_{t+1}$ is given by the fixed aggregate laws of motion.

2. Given $k_{t+1}$, and $m_{t}$ found in the previous step, solve the following non-linear equation for $c$

$$
u_{c}\left(c_{t}, m_{t}\right)-\beta E_{t}\left[\left(1+\left(1-\tau_{t+1}^{c}\right) r_{t+1}\right) v_{a}^{0}\left(a_{t+1}, e_{t+1} ; \pi_{t+1}, K_{t+1}\right)\right]=0
$$

given $v_{a}^{0}\left(a_{t+1}, e_{t+1} ; \pi_{t+1}, K_{t+1}\right)$ where $a_{t+1}=\left(1+\left(1-\tau_{t+1}^{c}\right) r_{t+1}\right) k_{t+1}+\frac{m_{t}}{1+\pi_{t+1}}$, and $K_{t+1}$ is given by the fixed aggregate laws of motion. 